\title{
Provenance Study through Analysis of Microstructural Characteristics Using an Optical Microscope and Scanning Electron Microscopy for Goryeo Celadon Excavated from the Seabed
}

\author{
Han Min-su* \\ Conservation Science Division, National Research Institute of Cultural Heritage, 132 Munji-ro, Yuseong-gu, \\ Daejeon 305-380, Republic of Korea
}

\begin{abstract}
This paper aims at identifying the provenance of Goryeo celadons by understanding its microstructural characteristics, such as particles, blisters, forms and amount of pores, and the presence of crystal formation, bodies, and glazes and its boundary, using an optical microscope and scanning electron microscopy (SEM). The analysis of the reproduced samples shows that the glazed layer of the sherd fired at higher temperatures has lower viscosity and therefore it encourages the blisters to be combined together and the layer to become more transparent. In addition, the result showed that the vitrification and melting process of clay minerals such as feldspars and quartzs on the bodies was accelerated for those samples. To factor such characteristics of the microstructure and apply it to the sherds, the samples could be divided into six categories based on status, such as small particles with many small pores or mainly large and small circular pores in the bodies, only a limited number of varied sized blisters in the glazes, and a few blisters and needle-shaped crystals on the boundary surface. In conclusion, the analysis of the microstructural characteristics using an optical microscope and SEM have proven to be useful as a categorizing reference factor in a provenance study on Goryeo celadons.
\end{abstract}

Key words: Goryeo celadon, microstructure, provenance, seabed, optical microscope, SEM

\section{INTRODUCTION}

The study of Goryeo celadon is significant in terms of its material characteristics and the techniques used in its production, spanning the 9th-14th centuries (Kang, 1989; Yun, 1994).

A scientific study of Goryeo celadon is considerably important in terms of its historical importance and scientific significance. In other countries, the study of the components of the glaze and the microstructure of Goryeo celadons relative to that of Chinese ceramics began in the late 1980s (Vandiver et al., 1989; Newman, 1991; Vandiver, 1991).

A provenance study is particularly significant as it allows us to determine the process of manufacturetransport-consumption. Further, it is closely related to the cultural exchange. In general terms, this study is based on petrologic and mineralogic viewpoints that reflect the chemical characteristics of the area, as the target material has properties attributed to its origin and its study has been consistently carried out using elemental and statistical analysis of excavated ceramic sherds (Dickinson, 1982). However, among the main constituents of clay, minerals such as quartz, members of the feldspar group (feldspar, microcline, orthoclase, albite), and those of the mica group (biotite, muscovite) produce various physical and chemical reactions, leading to the formation of new minerals, extinction,

() MICROSCOPY SOCIETY OF AMERICA 2013

${ }^{\star}$ Corresponding author. E-mail: dormer@korea.kr or phase transition, and this, in consequence, leads to deformation of crystals and microstructures. In other words, the characteristics of microstructures can be used as a classification factor that enables estimation of the manufacturing technique and the provenance of Goryeo celadons.

The microstructural characteristics of Goryeo celadons were examined using optical microscopy and scanning electron microscopy (SEM). With the acquired results, a provenance study was carried out to understand the corelationship between Goryeo celadon sherds excavated from the seabed and celadon sherds from kiln sites by identifying the production district of the sherds.

\section{Materials and Methods}

Samples were chosen and divided into three groups: (1) Group I (early, advance age); (2) Group II (middle, golden age); (3) Group III (late, decline age). For the analysis and understanding of each period, the samples were categorized by Sipleedongpado (Group I), Biando (Group II), and Doripo (Group III), matching one place and each seabed excavation site and 14 kiln sites. A total of 213 sherds were selected by the categorization process and analyzed. Table 1 gives information on the kiln sites and seabeds investigated in this study.

Celadon sherds were cut using a diamond cutting wheel (Minitom, Struers Co., Denmark) and mounted in epoxy after the surface was cleaned using an ultrasonic cleaner. Surfaces of the mounted samples were polished using sand 
Table 1. Information about the Kiln Sites and Seabeds Investigated in This Study.

\begin{tabular}{lllll}
\hline Group & \multicolumn{1}{c}{ Sites Name } & \multicolumn{1}{c}{ Location } & \multicolumn{1}{c}{ Period } & Excavated Type \\
\hline I (Early) & Sipleedongpado (SL) & Jeonbuck Gunsan & M11C-E12C & Seabed \\
& Jinsan-ri (JNS) & Jeonnam Haenam & L10C-E12C & Kiln site \\
& Sindeok-ri (SND) & Jeonnam Haenam & L9C-L11C & Kiln site \\
& Chosong-ri (CS) & Jeonnam Haenam & L10C-L11C & Kiln site \\
& Yonggye-ri (YG) & Jeonbuck Gochang & E10C-E12C & Kiln site \\
& Yongun-ri No. 16 (16YU) & Jeonnam Gangjin & E9C-E11C & Kiln site \\
& Yongun-ri No. 63 (63YU) & Jeonnam Gangjin & E9C-L10C & Kiln site \\
II (Middle) & Biando (BA) & Jeonbuck Gunsan & M12C-L12C & Seabed \\
& Jinseo-ri (JS) & Jeonbuck Buan & E12C-L12C & Kiln site \\
& Yucheon-ri (YC) & Jeonbuck Buan & M12C-E13C & Kiln site \\
& Sadang-ri No.7 (7SD) & Jeonnam Gangjin & M12C-L12C & Kiln site \\
& Sadang-ri No.9 (9SD) & Jeonnam Gangjin & L12C-E14C & Kiln site \\
& Sadang-ri No.10 (10SD) & Jeonnam Gangjin & L12C-L14C & Kiln site \\
& Gyeyul-ri No. 23 (23GY) & Jeonnam Gangjin & L11C-L12C & Kiln site \\
III (Later-Inlay) & Doripo (DR) & Jeonnam Muan & M14-L14C & Seabed \\
& Sadang-ri No. 10A IN (10SDA IN) & Jeonnam Gangjin & E14C-L14C & Kiln site \\
& Sadang-ri No. 10B IN (10SDB IN) & Jeonnam Gangjin & M14C-L14C & Kiln site \\
\hline
\end{tabular}

paper $(\# 120-\# 4,000)$ and polished with polishing cloth (3 $\mu \mathrm{m}, 1 \mu \mathrm{m})$. The polished sections were cleaned with ethyl alcohol (99.99\%) and etched with hydrofluoric acid ( $5 \mathrm{~mL}$; deionized water, $25 \mathrm{~mL}$ ) for 5-30 s after drying. Clay and glaze layers of the polished cross-sections were observed by means of an optical microscope (Axiotech 100HD/ Progress 3012, Carl Zeiss, Germany) and examined using an Image Analyzer (KS 300 System, Carl Zeiss). In addition, the microstructures of particles, their conditions, and secondary minerals were analyzed using SEM.

\section{Results}

\section{Analytical Results of Microstructural Characteristics Using an Optical Microscope}

Compared with previous studies (Lee, 1998, 2001; Lee \& Koh, 2002), the Goryeo celadon sherds excavated from the Sipleedongpado seabed (Group I) contained either circular or angulate quartz particles, including pores of various sizes. In addition, considering that blisters and needle-shaped crystals (anorthite) were rarely observed, as mentioned in previous studies (Lee \& Koh, 2002) on ceramics, the transparent glaze layers might have been fired at a temperature that activated insufficient vitrification. Sherds containing angulate quartz particles, small blisters, and needle-shaped crystals were found in the Jinsan-ri, chosong-ri, and Younggye-ri kiln sites. On the other hand, in the case of celadon sherds excavated from the Yongun-ri kiln site, quartz particles remained unmelted. With respect to the celadon sherds from yongun-ri No. 63, in particular, which include needle-shaped crystals in the boundary sections of the layer, it is assumed that they were fired at a temperature exceeding $1,200^{\circ} \mathrm{C}$ and cooled down slowly (Lee \& Koh, 2002).

Considering that Goryeo celadon sherds excavated from the Biando seabed (Group II) have regular small and large circular pores within the clay, it is possible to assume that glaze layers had melted properly and formed a few blisters. Needle-shaped crystals on the boundary sections of the layer suggest that they were fired at an appropriate temperature, at just over $1,200^{\circ} \mathrm{C}$. Goryeo celadon sherds from jinsan-ri and yucheon-ri, which are assumed to be the production kiln sites of the Biando sherds, have circular particles and a fine structure due to appropriate firing. Moreover, there is no "bingyoel" (thin wrinkles formed in the glaze layers), and the anorthite of the needle-shaped crystals with a mixture of large and small pores is observed. However, there are exceptions in that celadon sherds from Sadang-ri No. 9 showed many blisters in the glaze layers and Gyeyul-ri sherds had circular fine particles, which did not melt completely.

Goryeo celadon sherds excavated from the Doripo seabed (Group III) showed circular quartz particles as well as pores in the clay, indicating that they were fired at a high temperature for a long time. The glaze layers are generally without bingyoel, with a few blisters and needle-shaped crystals existing on the boundary sections of the layer. A unique characteristic is that many crystals have formed along the boundary layers on the inlaid area. In the case of celadon sherds of the "A" kiln of Sadang-ri No. 10 in Kangjin, assumed as the production kiln site of the celadon sherds, like sherds from Doripo, circular quartz particles were seen to have partially remained and pores had developed in circular shape. In addition, the glaze layers and inlaid area also showed characteristics similar to those of Doripo celadon sherds. On the other hand, Sadang-ri No. 10B celadon sherds had irregularly sized particles and some of them had irregular pores.

\section{Analysis Result of the Microstructural Characteristics Using SEM}

Figure 1A describes the melt state of feldspar in clay. Many Goryeo celadon sherds excavated from the seabed or kiln 

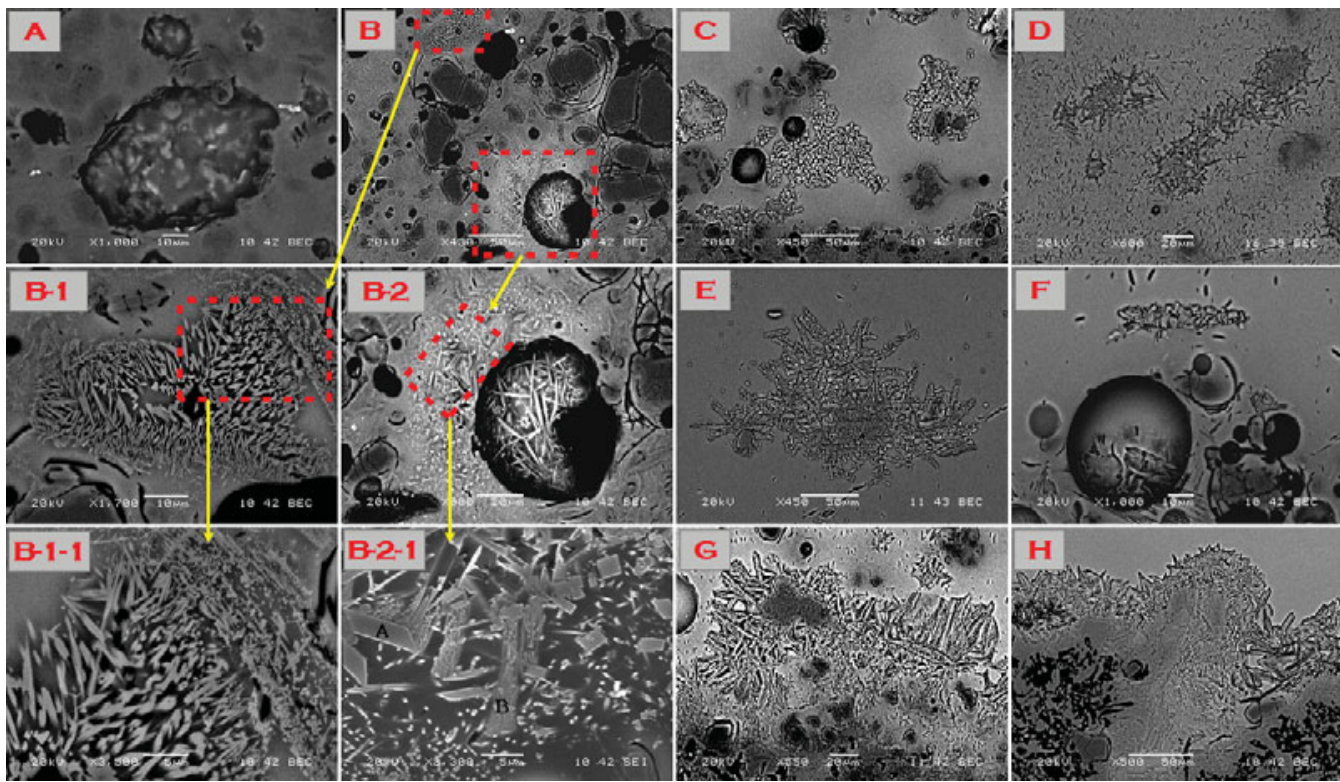

Figure 1. Specific image of microstructure of bodies and glazes for the Goryeo celadons observed by scanning electron microscope (SEM) image enabled to reconstruct not only firing environment based on size and shape of pores, and status of quartz particles in the bodies and glaze, but also firing temperature and raw material properties based on the grown degree of crystal phases of anorthite. The section of Analysis Result of Microstructural Characteristic Using SEM of this paper can be referred for the details.

sites showed an incomplete melt status due to being fired at a low temperature. Figure 1B shows that various types of mullite crystals formed in the clay, like Figures 1B-1-1 and 1B$2-1$. The result of the elemental composition of Figure 1B2-1 conducted by energy-dispersive spectrometer shows that traipozoidal or needle-shaped crystals of Figure 1A were Al-rich and that particle in Figure 1B, which are irregular crystals, contained mainly Fe. Figures $1 \mathrm{C}-1 \mathrm{~F}$ shows anorthite crystals grown in the glaze layers and having various crystal phases such as a needle-shape phase and a snow-crystalshape phase. Figures $1 \mathrm{G}$ and $1 \mathrm{H}$ show anorthites grown on the border between the white inlay and the glaze layers.

When the figures were examined more closely by each group, the celadon sherds of Group I were seen to show irregular pores and either circular or angulate quartz particles as a result of incomplete firing. On the whole, glaze layers melted well and showed a mixture of large and small pores with little bingyoel. Needle-shaped crystals are rarely observed in sherds other than those from the Yongun-ri and Sindeok-ri kiln sites.

It is believed that objects in Group II were fired well and this assumption gives the most appropriate firing temperature. The body has many pores and a small number of circular quartz particles. Glaze layers, except those of Gyeyul-ri No. 23 and Sadang-ri No. 10, seemed to have melted well and large and small particles with needleshaped crystals were observed.

It is assumed that objects of Group III were fired at a higher temperature compared with those of Group II. The body contained a small number of circular quartzs and pores. There was little bingyeol in the glaze layers and large and small pores were seen to partially exist and needle- shaped crystals to have grown on the boundary section of the layer. A great number of crystals had formed in the glaze layers, especially in the inlaid area.

It has already been reported that analysis of the microstructure by means of backscattered electron image is useful for the analysis of celadons, which are composed of various minerals (Lee, 1998) as the higher its atomic number, the brighter its display, and vice versa. From this perspect, it was also useful to analyze the microstructure of the Goryeo celadon sherds.

\section{Discussion}

From the microstructural analysis results of Goryeo celadon sherds excavated from seabeds and kiln sites using an optical microscope and SEM, each body and glaze of the Goryeo celadon sherds can be categorized into six types on the basis of common characteristics (Fig. 2, Table 2). The data thus acquired are classified below (Table 3 ).

The results enable us to ascertain which sherds have similarities with objects from which seabed. However, there is a limitation to the provenance study using the typological data established by microstructural analysis: some sherds show a slightly different microstructure from those excavated from the same area. Taking the glaze layer as an example, the reproduced celadon sherds show that the higher the temperature at which the sherd is fired, the lower its viscosity, and it causes blisters to combine together and its layer becomes more transparent. On the other hand, in the case of Goryeo celadon sherds, the microstructural characteristics are not identical, although they were excavated from same area. 


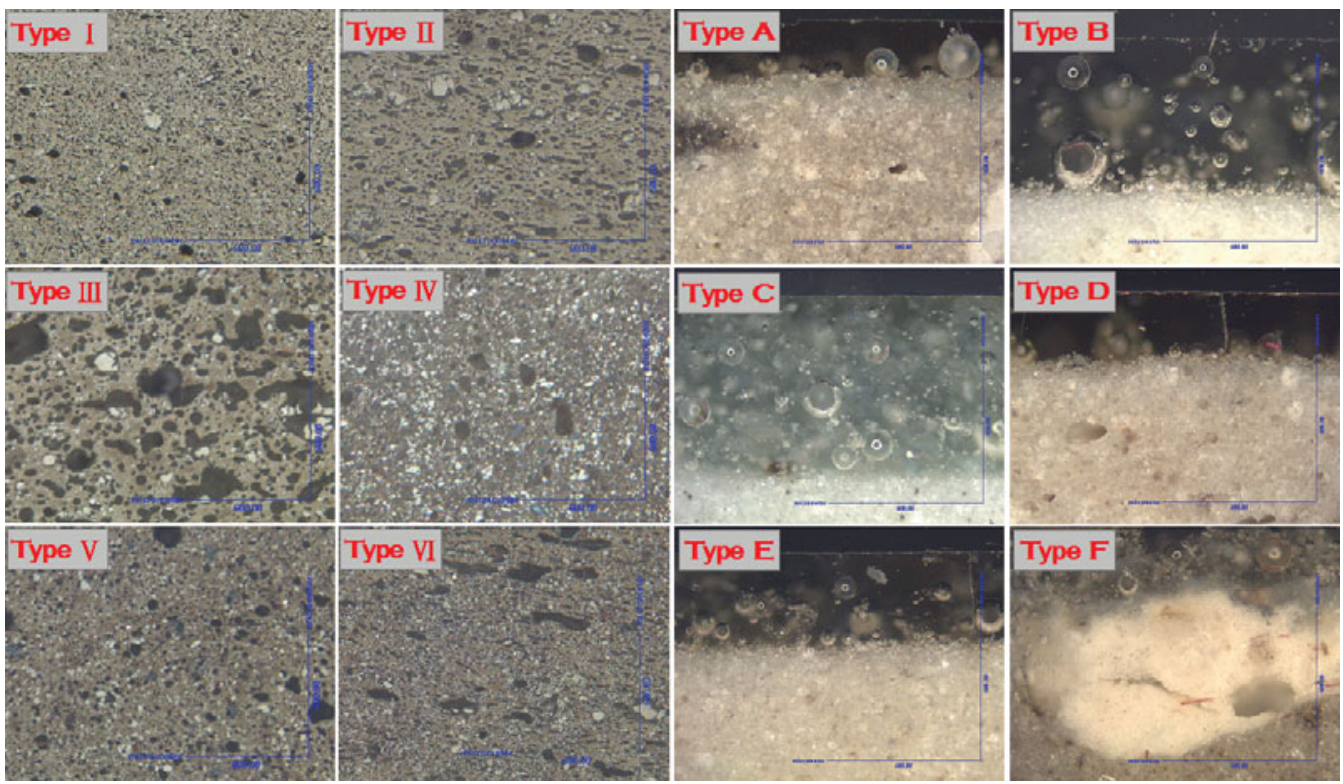

Figure 2. Six types of microstructural characteristics of bodies (Type I-VI) and glazes (Type A-F) for the Goryeo celadons based on an observation by optical microscope. (Categorization based on similar types of microstructure of the 213 sherds. Table 2 can be referred for the detailed characteristics of each type.)

The reason might be that they were not manufactured using high-purity raw materials and also the firing temperature was not constant because of various conditions such as types of kilns or wooden fuels. In particular, if samples have celadon's general characteristics, the body should have displayed vitrification and the glaze layer should have displayed blisters under the optical microscopic and SEM analysis. However, the presence of several fragments that did not display such characteristics makes grouping difficult

Table 2. Description of the Microtexture Characteristics in the Bodies and Glaze.

\begin{tabular}{|c|c|c|}
\hline Part & Type & Description \\
\hline \multirow[t]{6}{*}{ Body } & I & Small particles with many small pores \\
\hline & II & $\begin{array}{l}\text { Various sized particles and appropriate numbers } \\
\text { and sizes of pores }\end{array}$ \\
\hline & III & $\begin{array}{l}\text { Mainly large and small circular pores or large } \\
\text { pores }\end{array}$ \\
\hline & IV & $\begin{array}{l}\text { Mainly small circular particles and large and } \\
\text { small pores }\end{array}$ \\
\hline & $\mathrm{V}$ & Small circular particles and slightly large pores \\
\hline & VI & Small circular particles and irregular pores \\
\hline \multirow[t]{6}{*}{ Glaze } & A & A few blisters and transparent glaze layer \\
\hline & $\mathrm{B}$ & Various sized blisters and transparent glaze layer \\
\hline & $\mathrm{C}$ & Only a limited number of various sized blisters \\
\hline & $\mathrm{D}$ & $\begin{array}{l}\text { A few blisters and needle-shaped crystals on the } \\
\text { boundary surface }\end{array}$ \\
\hline & $\mathrm{E}$ & $\begin{array}{l}\text { A few blisters and quartz in the glaze layer } \\
\text { and needle-shaped crystals in the glaze layer } \\
\text { or boundary surface }\end{array}$ \\
\hline & $\mathrm{F}$ & $\begin{array}{l}\text { A large number of blisters and quartz in } \\
\text { the glaze layer and needle-shaped crystals in } \\
\text { the glaze layer or boundary surface }\end{array}$ \\
\hline
\end{tabular}

in the study. The reason could be that the very slow alteration progressed in the used raw material that had a high amount of $\mathrm{Al}_{2} \mathrm{O}_{3}$ and $\mathrm{SiO}_{2}$ with a little flux such as $\mathrm{CaO}$. The firing environment can be another cause, as it restricts physical and chemical reactions within the material. However, vitrescence might be progressed for the less-fired sherds and glaze at higher firing temperature or increased firing time. In addition, particles within the clay and the glaze might be melted. As mentioned in several previous studies (Lee, 1998, 2001; Lee \& Koh, 2002), it is believed that glaze layers become transparent, forming large blisters and removing small ones away at a higher temperature.

\section{CONCLUSIONS}

The development processes of Goryeo celadons were categorized into three stages (early, middle, and late) and then a provenance study was carried out according to the correlation of the microstructural characteristics of 123 representative celadon sherds excavated from 17 sites such as seabeds and kiln sites. As a result, the microstructural characteristics of bodies and glazes (including boundary sections) could be categorized into six types based on the shape, amount of particles, pores, and blisters and presence of crystals. All the corelated factors between the acquired typological characteristics and the three groups suggest that Sipleedongpado (Group I) may have been produced in the Jinsan-ri site, Biando (Group II) in the Yucheon-ri region, and Doripo (Group III) in the Sadang-ri area.

To conclude, the analysis yielded useful results, although only a simple visual microscopic observation was made without applying other scientific methods (e.g., statistical analysis of trace elements) that are generally used in provenance studies of objects made from clay, such as 
Table 3. Characteristics of the Microtexture in the Bodies and Glaze.

\begin{tabular}{|c|c|c|c|c|c|c|c|c|c|c|}
\hline \multirow[b]{3}{*}{ Kiln Sites } & \multicolumn{5}{|c|}{ Body $^{a}$} & \multirow{2}{*}{\multicolumn{3}{|c|}{$\frac{\text { Glaze }^{\mathrm{b}}}{\text { Bubble }}$}} & \multirow{2}{*}{\multicolumn{2}{|c|}{$\frac{\text { Boundary }^{\mathrm{c}}}{\text { Bubble }}$}} \\
\hline & \multirow[b]{2}{*}{ Type } & \multicolumn{2}{|c|}{ Pore } & \multicolumn{2}{|c|}{ Silica } & & & & & \\
\hline & & Size & Number & State & Number & Type & Size & Number & Size & Number \\
\hline Sipleedongpado & I & L\&S & M & $A \& R$ & M & A & L\&S & $\mathrm{L}$ & S & M \\
\hline Jinsan-ri & I & L\&S & M & $\mathrm{A} \& \mathrm{R}$ & $\mathrm{L}$ & A & L\&S & $\mathrm{L}$ & S & $\mathrm{L}$ \\
\hline Sindeok-ri & II & S & $\mathrm{L}$ & $A \& R$ & $\mathrm{~L}$ & B & $\mathrm{L}$ & $\mathrm{L}$ & S & $\mathrm{L}$ \\
\hline Chosong-ri & I & S & M & $\mathrm{R}$ & $\mathrm{L}$ & A & $\mathrm{L}$ & $\mathrm{L}$ & S & M \\
\hline Yonggye-ri & I & S & $\mathrm{L}$ & $\mathrm{R}$ & $\mathrm{L}$ & A & $\mathrm{L}$ & $\mathrm{L}$ & S & $\mathrm{L}$ \\
\hline Yongun-ri No. 16 & IV & $S$ & $\mathrm{~L}$ & $A \& R$ & M & $\mathrm{C}$ & L\&S & M & $S$ & $\mathrm{~L}$ \\
\hline Yongun-ri No. 63 & VI & L\&S & M & $A \& R$ & M & $\mathrm{D}$ & $\mathrm{L}$ & $\mathrm{L}$ & S & $\mathrm{L}$ \\
\hline Biando & II & L\&S & $\mathrm{L}$ & $\mathrm{R}$ & $\mathrm{L}$ & $\mathrm{D}$ & $\mathrm{L}$ & $\mathrm{L}$ & S & M \\
\hline Jinseo-ri & II & L\&S & M & $\mathrm{R}$ & $\mathrm{L}$ & $\mathrm{D}(\mathrm{E})$ & L\&S & $\mathrm{L}$ & S & $\mathrm{L}$ \\
\hline Yucheon-ri & II & L\&S & M & $\mathrm{R}$ & $\mathrm{L}$ & $\mathrm{D}$ & $\mathrm{L}$ & $\mathrm{L}$ & S & $\mathrm{L}$ \\
\hline Sadang-ri No. 7 & II & L\&S & $\mathrm{L}$ & $\mathrm{R}$ & $\mathrm{L}$ & $\mathrm{D}$ & L\&S & M & S & $\mathrm{L}$ \\
\hline Sadang-ri No. 9 & II & L\&S & $\mathrm{L}$ & $\mathrm{R}$ & $\mathrm{L}$ & $\mathrm{C}$ & L\&S & M & $S$ & $\mathrm{~L}$ \\
\hline Sadang-ri No. 10 & II & L\&S & $\mathrm{L}$ & $\mathrm{R}$ & $\mathrm{L}$ & $\mathrm{D}$ & L\&S & M & $S$ & $\mathrm{~L}$ \\
\hline Gyeyul-ri No. 23 & IV & L\&S & $\mathrm{L}$ & $\mathrm{R}$ & $\mathrm{L}$ & $\mathrm{C}$ & L\&S & M & S & M \\
\hline Doripo & III & $\mathrm{L}$ & $\mathrm{L}$ & $\mathrm{R}$ & $\mathrm{L}$ & $\mathrm{D}(\mathrm{F})$ & $\mathrm{L}$ & $\mathrm{L}$ & S & $\mathrm{L}$ \\
\hline Sadang-ri No. 10A IN & III & $\mathrm{L}$ & $\mathrm{L}$ & $\mathrm{R}$ & $\mathrm{L}$ & $\mathrm{D}(\mathrm{F})$ & L\&S & M & S & $\mathrm{L}$ \\
\hline Sadang-ri No. 10B IN & $\mathrm{V}$ & L\&S & $\mathrm{L}$ & $\mathrm{R}$ & $\mathrm{L}$ & $\mathrm{D}$ & L\&S & $\mathrm{L}$ & S & $\mathrm{L}$ \\
\hline
\end{tabular}

aPore size: L, large; M, middle; S, small/number; M, many; L, little. Silica state: A, angle; R, round/number; M, many, L, little.

${ }^{b}$ State: G, good; M, middle. Bubble size: L, large; M, middle; S, small/number; M, many; L, little.

'Bubble size: L, large; $M$, middle; S, small/number; M, many; L, little

pottery or ceramics, including Goryeo celadon. Therefore, it is believed that estimation of the firing temperature and determination of provenance by analyzing the microstructural characteristics can be carried out if representative specimens are secured and error limits caused by heterogeneities of particles and pores are reduced.

\section{ACKNOWLEDGMENTS}

This study was executed as a part of the Conservation Restoration Technology Research and Development Project, which was conducted by the National Research Institute of Cultural Heritage. We express our gratitude to the National Research Institute of Maritime Cultural Heritage, Gangjin Cheongja Museum, and Wonkwang University Museum.

\section{REFERENCES}

Dickinson, W.R. (1982). Temper sands from prehistory sherds excavated at Pemrang site on Yap and from nearby Ngulu Atoll. Bull Indo-Pacific Prehistory Association 3, 115-117.

KANG, K.S. (1989). Korean Ceramic History. Seoul, Korea: Iljisa.

LeE, Y.E. (1998). Compositional and Microstructural Study of Choson Punchong. Seoul, Korea: Chung-Ang University.
LeE, Y.E. \& КоH, K.S. (2002). A microstructural study on firing process of Korean traditional ceramics; Punch'ong from Ch'unghyodong, Kwangju. J Kor Chem Soc 46, 32-133.

LeE, Y.S. (2001). Analytical and Statistical Study on the Raw Materials of Korean Traditional Ceramics. Seoul, Korea: Chung-Ang University.

Newman, R. (1991). The composition and microstructural study of Korean celadon glaze of the 11th to 15th centuries. In Materials Issues in Art and Archaeology II, Vandiver, P.B., Druzik, J. \& Segan, G. (Eds.), pp. 423-434. Pittsburgh, PA: Materials Research Society.

VAndiver, P.B. (1991). The technology of Korean celadons. In The Resistance of Jade and the Clarity of Water-Korean Ceramics from Ataka Collection, Itoh, I. \& Mino, Y. (Eds.), pp. 151-158. Chicago: The Art Institute of Chicago and Hudson Hills Press.

VAndiver, P.B., Cort, L.A. \& HANdweker, C.A. (1989). Variations in the practice of ceramic technology in different culture: A comparison of Korean and Chinese celadon glazes. In CrossCraft and Cross-Cultural Interactions in Ceramics, Notis, M.D. (Ed.), pp. 347-388. Westerville, OH: American Ceramics Society.

Yun, Y.I. (1994). Studies in Korean Ceramics History. Seoul, Korea: Munyech'ulpansa. 